Research Article

\title{
Effects of Welding Heat Input on Microstructure and Electrochemical Behavior of Flux-Cored Arc-Welded Q690 HSLA Steel
}

\author{
Kai Wang $\left(\mathbb{D},{ }^{1,2}\right.$ Qinghua Lu, ${ }^{1}$ Yaoyong Yi, ${ }^{2}$ Jianglong Yi $\left(\mathbb{D},{ }^{2}\right.$ Ben Niu, ${ }^{2}$ Zexin Jiang, \\ and Jinjun $\mathrm{Ma}^{3}$ \\ ${ }^{1}$ Foshan University, Foshan, China \\ ${ }^{2}$ Guangdong Welding Institute (China-Ukraine E. O. Paton Institute of Welding), Guangzhou, China \\ ${ }^{3}$ Guangzhou Shipyard International Co., Ltd., Guangzhou, China
}

Correspondence should be addressed to Kai Wang; hfutwk927@gmail.com

Received 28 August 2017; Revised 3 December 2017; Accepted 13 December 2017; Published 30 January 2018

Academic Editor: Patrice Berthod

Copyright (c) 2018 Kai Wang et al. This is an open access article distributed under the Creative Commons Attribution License, which permits unrestricted use, distribution, and reproduction in any medium, provided the original work is properly cited.

In this work, the weld metal (WM) for the Q690 high-strength low-alloy (HSLA) steel was prepared through flux-cored arc welding (FCAW) at $10 \mathrm{~kJ} / \mathrm{cm}$ and $20 \mathrm{~kJ} / \mathrm{cm}$ heat inputs. The effect of welding heat input on the relationship between the microstructural factors and the electrochemical behavior of the FCAW Q690 steel was studied. Due to the fine grain and acicular ferrite affected by the $10 \mathrm{~kJ} / \mathrm{cm}$ low heat input, the WM presented similar electrochemical behavior to the Q690 base metal, which would minimize the risk of galvanic corrosion. Also, at $20 \mathrm{~kJ} / \mathrm{cm}$ of high welding heat input, the WM with higher-sized bainite structure was prone to galvanic corrosion risk minimization.

\section{Introduction}

The Q690 steel, also called ASTM A514 steel, is well known as a typical low-carbon bainite high-strength low-alloy (HSLA) steel with excellent low temperature toughness and weldability. It is usually prepared through quenching and tempering processing. Chen et al. researched the microstructure and properties of the Q690 HSLA steel, as well as the hot deformation behavior and phase transformation during hightemperature deformation and compression [1], establishing a good mathematical model of the effective grain boundary area and the compression amount [2]. Owing to the corresponding high performance, this steel has been widely utilized in various fields, especially in the offshore engineering industry with a maximum thickness of $300 \mathrm{~mm}[3,4]$. These offshore engineering equipment have high requirements to the mechanical quality of the weld joints. In general, the researchers and technicians have mainly focused on the strength and toughness of the weld joints of the Q690 steel [5], developing various welding materials for the Q690 steel with an impact energy exceeding $69 \mathrm{~kJ}$ at $-40^{\circ} \mathrm{C}[6]$.
Corrosion is always a severe problem in the offshore engineering industry during the structures serving in a highly corrosive ocean environment. Despite that fact that anticorrosive protection methods such as the paintings and electrochemical treatments are widely applied, the corrosion of the offshore structures is still unavoidable and severe. In the offshore structures, the weld joints are the most probable regions that are inclined to galvanic corrosion coupling with the base metal (BM) and the welded metals (WMs) $[7,8]$. Therefore, the weld joints are of vital importance to the safety and lifetime of offshore structures in the industry. Adversely, studies focused on the electrochemical behavior of the welded Q690 steel are scarcely reported, particularly with inclination to the galvanic interaction between the WM and BM in weld joints.

Flux-cored arc welding (FCAW) process is a gas metal arc welding, where continuous flux-cored wires are utilized. Given the corresponding peculiar advantages and high productivity, the FCAW is currently widely utilized in many engineering industries for joining metals, especially for the Q690 HSLA steel welding [9]. Once the flux-cored wire, the $\mathrm{BM}$, and the shielding gas are preset, the properties of FCAW joints are 
Table 1: Chemical composition of the Q690 steel in wt.\%.

\begin{tabular}{lccccccc}
\hline $\mathrm{C}$ & $\mathrm{Si}$ & $\mathrm{Mn}$ & $\mathrm{P}$ & $\mathrm{S}$ & $\mathrm{Ni}$ & $\mathrm{Cr}$ & $\mathrm{Mo}$ \\
\hline$\leq 0.09$ & $0.2 \sim 0.55$ & $1.4 \sim 1.8$ & $\leq 0.01$ & $\leq 0.01$ & $0.9 \sim 2.6$ & $\leq 0.05$ & $0.25 \sim 0.55$ \\
\hline
\end{tabular}

TABLE 2: Mechanical properties of the Q690 steel.

\begin{tabular}{lccc}
\hline Yield strength $(\mathrm{MPa})$ & Tensile strength $(\mathrm{MPa})$ & Elongation $(\%)$ & $-20^{\circ} \mathrm{C}$ impact energy $(\mathrm{J})$ \\
\hline $700 \sim 740$ & $680 \sim 690$ & $\geq 16$ & $\geq 69$ \\
\hline
\end{tabular}

TABLE 3: Welding parameters of each welding process.

\begin{tabular}{lcccccc}
\hline Number & $\begin{array}{c}\text { Preheating temperature } \\
\left({ }^{\circ} \mathrm{C}\right)\end{array}$ & $\begin{array}{c}\text { Current } \\
(\mathrm{A})\end{array}$ & $\begin{array}{c}\text { Voltage } \\
(\mathrm{V})\end{array}$ & $\begin{array}{c}\text { Interpass temperature } \\
\left({ }^{\circ} \mathrm{C}\right)\end{array}$ & $\begin{array}{c}\text { Welding speed } \\
\left(\mathrm{cm} \cdot \mathrm{min}^{-1}\right)\end{array}$ & $\begin{array}{c}\text { Welding heat input } \\
\left(\mathrm{kJ} \cdot \mathrm{cm}^{-1}\right)\end{array}$ \\
\hline 1 & 150 & 200 & 25 & 150 & 30 & 10 \\
2 & 150 & 240 & 28 & 150 & 20 & 20 \\
\hline
\end{tabular}

mainly affected by the weld metal (WM) at various welding parameters [10-12]. Jindal et al. [13] demonstrated that the high-quality WM could be obtained through the welding parameter control within an optimized range. Indeed, the welding heat input is the most aggregative indicator of welding parameters such as the welding current, the voltages, and the speeds [14]. The welding heat input is one of the most important factors for the combination property determination of the WM [15]. In contrast, only rare researches exist regarding the electrochemical behavior of the FCAW Q690 HSLA steel, particularly with respect to the welding heat input effect.

Based on the previous data, the Q690 steel was overlay welded through the FCAW technology under two common parameters for industry in this work. The welding heat input effect on the relationship between the microstructural factors and the electrochemical behavior of the Q690 steel BM, and FCAW WMs were investigated to evaluate the galvanic tendency. The present work consequently would serve only as a preliminary investigation for reference in future studies on FCAW welding of the Q690 HSLA steel. Moreover, detailed studies on in situ stress corrosion with a scanning electrochemical microscope will be reported in a future work.

\section{Experimental Procedure}

The Q690 HSLA steel according to the GB/T 16270-2009 Chinese standard was utilized as the experimental BM prepared subsequently to quenching and tempering. The steel plate size was $300 \mathrm{~mm} \times 150 \mathrm{~mm} \times 14 \mathrm{~mm}$. Table 1 presents the chemical composition of the Q690 BM, and Table 2 presents the mechanical properties. The flux-cored wire (type: OK Tubrod 15.09, produced by ESAB company) of $1.2 \mathrm{~mm}$ in diameter was utilized as the welding material. Five layers were overlaid on the BM plate to acquire the WM. A welding machine (type: Taurus 421 forceArc DW, produced by EWM company) was utilized, with the mode of no pulse constant voltage-DC reverse connection. A mixture of $80 \% \mathrm{Ar}+20 \% \mathrm{CO}_{2}$ was selected. The FCAW experiments were conducted at the welding heat inputs of $10 \mathrm{~kJ} / \mathrm{cm}(\# 1)$ and $20 \mathrm{~kJ} / \mathrm{cm}(\# 2)$. The welding parameters are presented in Table 3. The Q690 BM was marked as sample \#3. The weld samples were cooled down in the air at room temperature subsequently to welding, and consequently, the WM was obtained following the removal of the surficial layer and heat-affected zone through linear cutting. The final samples were of $10 \mathrm{~mm} \times 10 \mathrm{~mm} \times 0.5 \mathrm{~mm}$ in size. Subsequently to polishing, grinding, and etching, each WM sample was well prepared for observation and analysis with the JXA-8100 scanning probe microscope (SEM).

Prior to electrochemical testing, the samples were polished gradually with 200 to 2000 grit sand papers, degreased with acetone, and washed with the distilled water, followed by drying with a blower. The working areas of the tested samples were prepared at $1 \mathrm{~cm}^{2}$, whereas the remaining parts of the samples were sealed with resin. The electrochemical impedance spectroscopy (EIS) and the linear polarization (LP) tests were conducted through an Autolab PGSTAT302N electrochemical workstation with a three-electrode system. The working electrode was the tested sample $\left(1 \mathrm{~cm}^{2}\right.$ of working area), the auxiliary electrode was a Pt plate, and the reference electrode was $\mathrm{Ag} / \mathrm{AgCl}(3 \mathrm{~mol} / \mathrm{L} \cdot \mathrm{KCl})$. The electrolyte was a 3.5 wt.\% $\mathrm{NaCl}$ aqueous solution. Prior to testing, the working electrode was soaked in the electrolyte at the opencircuit potential (OCP) mode for $30 \mathrm{~min}$. The EIS mode was set at the OCP, with a frequency of $10^{-2} \sim 10^{4} \mathrm{~Hz}$ and an AC drive signal amplitude of $\pm 5 \mathrm{mV}$. The LP mode was set as the scanning potential range of $\pm 15 \mathrm{mV}$ versus OCP, with a scanning speed of $1 \mathrm{mV} / \mathrm{s}$.

\section{Results and Discussion}

3.1. Microstructure Analysis. The typical microstructure of the WMs at different welding heat inputs and the Q690 steel BM was observed through SEM, as presented in Figure 1. The microstructures of the Q690 BM were mainly of lath bainite, with abundant acicular ferrite island groups, as presented in Figure 1(c). At both low and high welding heat inputs, the WMs consisted of lath and granular bainites, with martensiteaustenite (M-A) islands distributed on the ferrite. Owing to the melting and solidification of the wire metal during FCAW, the grain sizes of WMs were of lower sized compared to those of the BM. The welding heat input contributed to the phase 


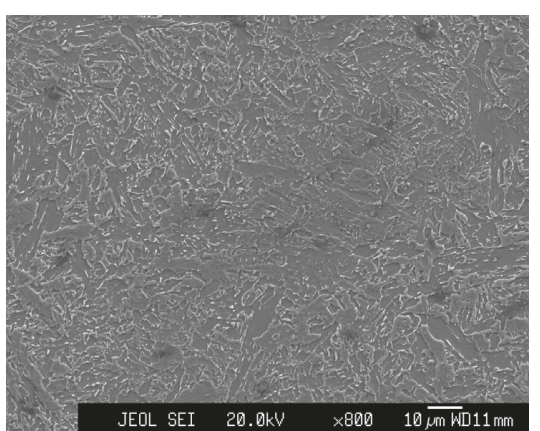

(a)

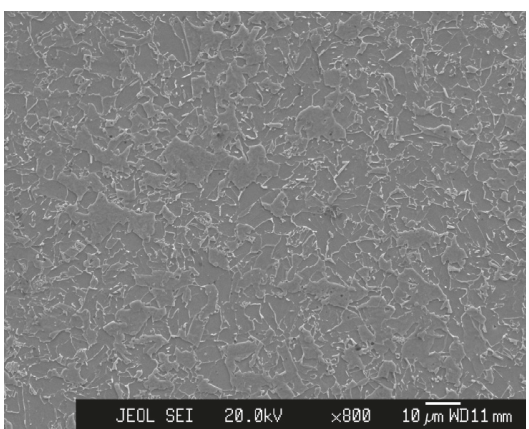

(b)

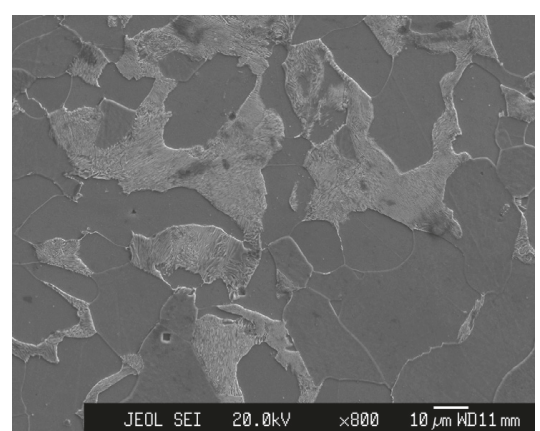

(c)

FIgure 1: Typical microstructure of WMs at welding heat inputs of (a) $10 \mathrm{~kJ} / \mathrm{cm}$ and (b) $20 \mathrm{~kJ} / \mathrm{cm}$, and (c) Q690 BM.

transformation of WMs. Through the welding heat input increase from $10 \mathrm{~kJ} / \mathrm{cm}$ to $20 \mathrm{~kJ} / \mathrm{cm}$, more grains were recrystallized. Simultaneously, the grains increased in size and became more homogeneous as presented in Figure 1(b), compared to the counterpart WM at a low welding heat input of $10 \mathrm{~kJ} / \mathrm{cm}$, as presented in Figure 1(a). The cooling rate was relevant to the welding heat input. This meant that the low cooling rate with $t_{8 / 5}$ was approximately $10 \mathrm{~s}$ at $10 \mathrm{~kJ} / \mathrm{cm}$ of welding heat input, whereas the high cooling rate with $t_{8 / 5}$ was approximately $20 \mathrm{~s}$ at $20 \mathrm{~kJ} / \mathrm{cm}$ of welding heat input [16]. The high cooling rate would induce the growth of factors such as the weld heat energy and the defect density, as well as the generation of a significantly quenched hardening structure. Moreover, the low cooling rate increased the austenitic isothermal time, which was unfavorable for the long-range diffusion of carbon atoms. The quantity of the carbon concentrated in the primary austenite would be suppressed, being affected by the cooling rate as well as the welding heat input, when the bainitic ferrite was generated during the bainitic transformation. Following this, the bainitic ferrite formation was prevented by the stabilization of the primary austenite, while the carbon concentration reached a critical value. Therefore, the residual austenite transformed into the retained austenite or M-A island that was distributed within the ferrite matrix. Subsequently, the lath and granular bainite microstructures were generated $[16,17]$. The effect of welding heat input and cooling rate on the growth of the bainitic structure was apparent. At the low welding heat input of $10 \mathrm{~kJ} / \mathrm{cm}$, low-sized and long narrow lath bainite and granular bainite with more acicular ferrite could be observed in the WM, as presented in Figure 1(a). Higher sizes of the lath and granular bainite as well as of M-A islands were observed in the WM at the high welding heat input of $20 \mathrm{~kJ} / \mathrm{cm}$, as presented in Figure 1(b). The effects caused by the welding heat input contributed to the bainitic ferrite growth; consequently, the bainite lath size of the WM was relatively higher at $20 \mathrm{~kJ} / \mathrm{cm}$ of high welding heat input.

3.2. Electrochemical Behavior. Figure 2 presents the linear polarization curves of the Q690 BM and WMs at different welding heat input conditions. The LP lines of the Q690 BM were the most stable with the most positive self-corrosion potential of $-0.543 \mathrm{~V}$, as compared to the counterpart of WMs. The self-corrosion potential of the WM at $10 \mathrm{~kJ} / \mathrm{cm}$

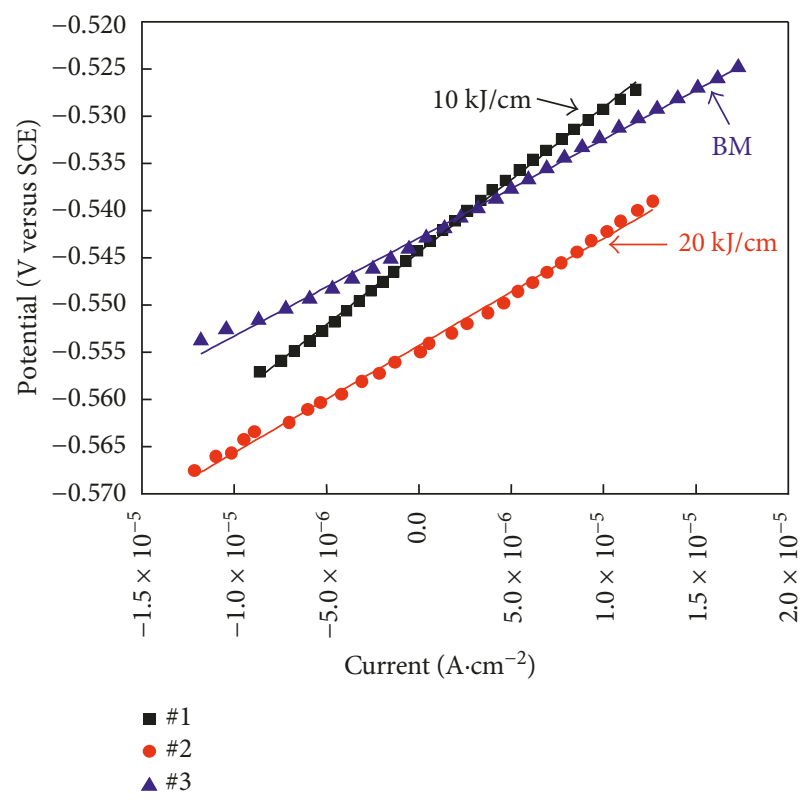

FIGURE 2: Linear polarization curves of WMs at different welding heat inputs and of the Q690 BM.

TABLE 4: Linear polarization resistances of WMs at different welding heat inputs and of the Q690 BM.

\begin{tabular}{lcc}
\hline Number & Sample condition & LPR $\left(\mathrm{Ohm} \cdot \mathrm{cm}^{2}\right)$ \\
\hline 1 & $10 \mathrm{~kJ} / \mathrm{cm}$ & 1532.38 \\
2 & $20 \mathrm{~kJ} / \mathrm{cm}$ & 1133.85 \\
3 & Q690 base metal & 1040.61 \\
\hline
\end{tabular}

was the second positive of $-0.545 \mathrm{~V}$ and quite similar to the $\mathrm{BM}$ value. It might be caused by the ferrite structure existence in the WM at low heat input, which would improve the electrode potential of the WM, similarly to the results of $\mathrm{Qu}$ et al. [18]. Through the heat input increase to $20 \mathrm{~kJ} / \mathrm{cm}$, the potential of the WM shifted negatively towards $-0.555 \mathrm{~V}$. However, at low or high welding heat input, the LP line trend was steady and linear, as demonstrated by the uniform microstructure from the SEM observation (Figure 1).

Table 4 presents the calculated linear polarization resistances (LPRs) of each sample. The LPR value of the low 


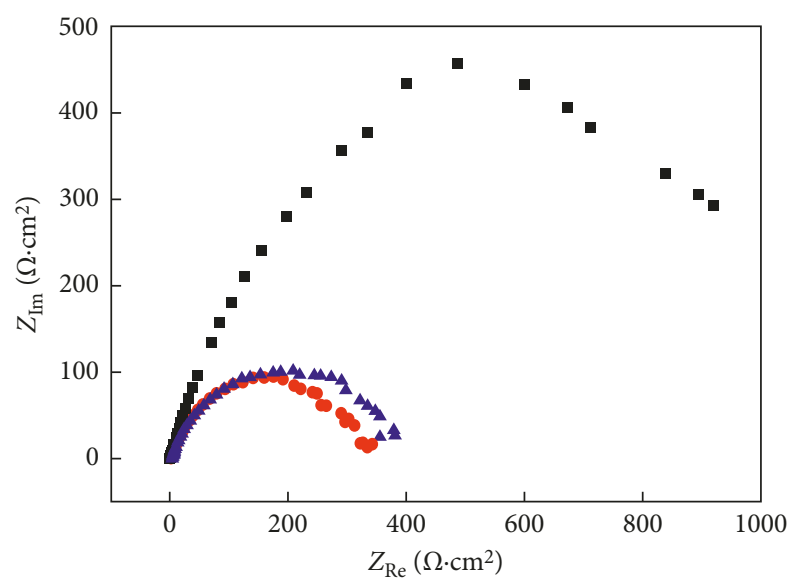

- $\# 1$

- $\# 2$

$\Delta$ \#3

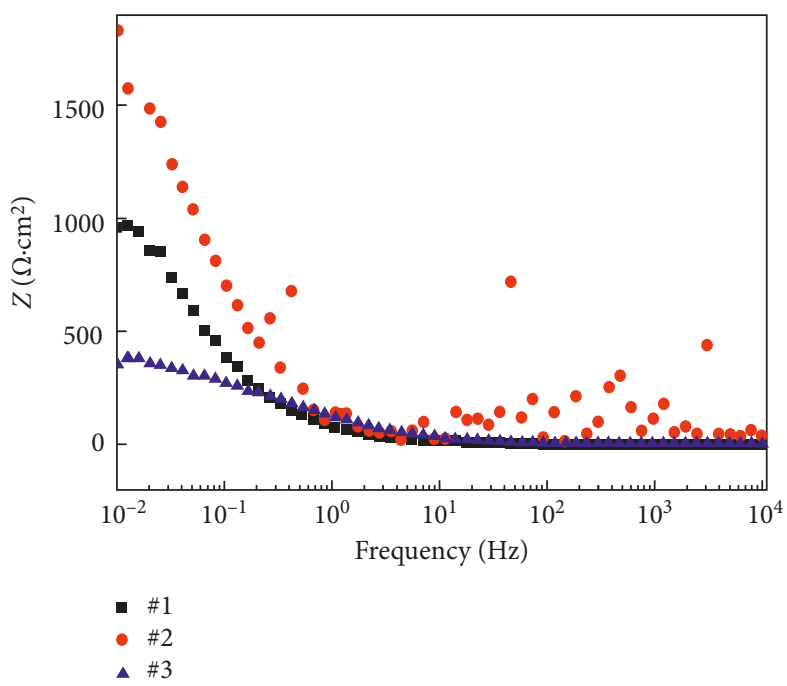

(b)

(a)

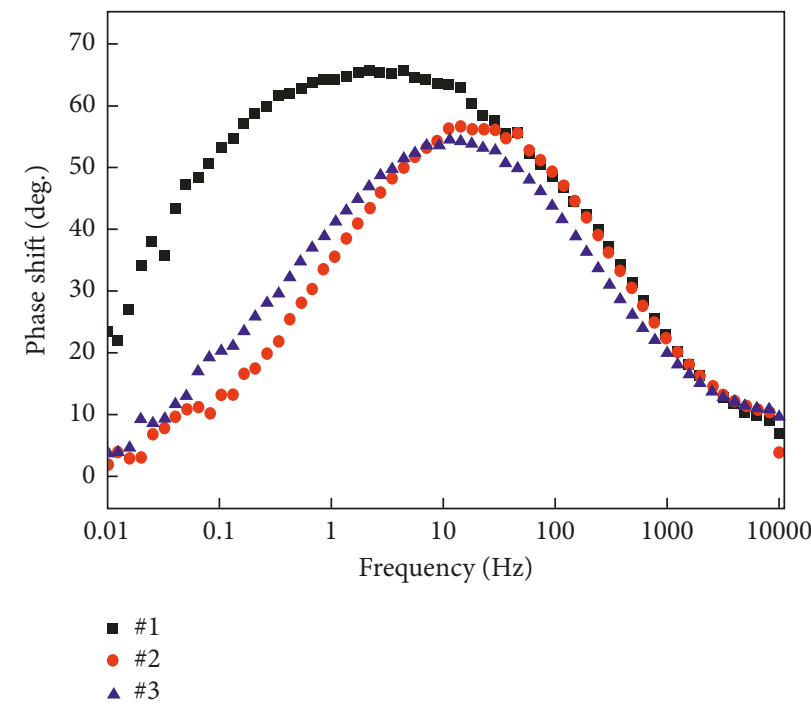

(c)

Figure 3: (a) Nyquist, (b) Bode, and (c) Bode-phase plots of WMs at different welding heat inputs and of the Q690 BM at OCP.

heating input WM (\#1) was $1532.38 \mathrm{Ohm} \cdot \mathrm{cm}^{2}$, for which the plot presented the highest slope. Also, the high heating input WM (\#2) presented a lower LRP value of $1133.85 \mathrm{Ohm} \cdot \mathrm{cm}^{2}$, which was similar to its Q690 BM counterpart of $1040.61 \mathrm{Ohm} \cdot \mathrm{cm}^{2}$. Both LPR values of the WMs were higher compared to those of the Q690 BM, for which the order was consistent with the sequence of the corresponding grain sizes.

The initial stage of corrosion reaction mainly depended on the electrochemical reactivity of the matrix. The differences in the grain size affected the surface activity of the matrix. Compared to the coarse-grained structure, the fine-grained structure had significantly higher grain boundary area, which could effectively improve the surface activity of the matrix. In this work, it was easier to accelerate the oxide film formation on the WM surface owing to the fine grains. Therefore, the WM could provide a significantly effective protection against corrosion, due to the corresponding higher LPR value. Specifically, the WM at lower heat input had an increased amount of acicular ferrite, which also increased the potential of the matrix. This led to the similar polarization behavior of the fine-grained WM with more acicular ferrite at low heat input and of the coarse-grained BM.

The EIS experiments of the WMs and Q690 BM in the 3.5 wt. $\% \mathrm{NaCl}$ solution were executed at OCP. The results are presented as Nyquist, Bode, and Bode-phase plots in Figure 3. All EIS plots of the WM (\#2) at $20 \mathrm{~kJ} / \mathrm{cm}$ displayed similar behavior to the Q690 BM. Both Nyquist plots of the WM (\#2) and BM (\#3) presented near-perfect semicircles, while the Nyquist plot of the WM (\#1) displayed an imperfect semicircle. The semicircle diameter of the WM $(\# 1)$ at $10 \mathrm{~kJ} / \mathrm{cm}$ was apparently higher compared to that of the WM (\#2) at $20 \mathrm{~kJ} / \mathrm{cm}$ 


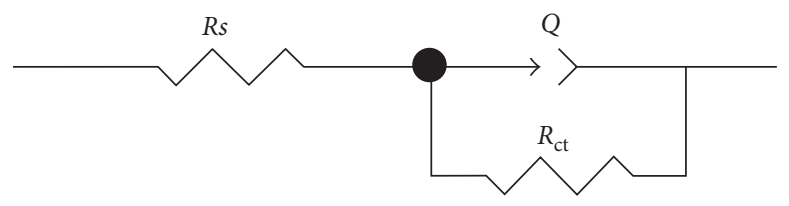

FIGURE 4: Best equivalent circuit used for experimental EIS data modeling.

TABLE 5: Variations in impedance parameters of EIS-tested samples.

\begin{tabular}{lcccccc}
\hline & $\# 1$ & & $\# 2$ & & & \\
& Value & Error (\%) & Value & Error (\%) & Value & Error (\%) \\
\hline$R_{s}\left(\Omega \cdot \mathrm{cm}^{2}\right)$ & 0.9837 & 1.89 & 4.352 & 1.54 & 3.423 & 1.43 \\
$Q\left(\Omega \cdot \mathrm{cm}^{2}\right)$ & $3.14 \times 10^{-3}$ & 1.54 & $1.43 \times 10^{-3}$ & 2.36 & $1.87 \times 10^{-3}$ \\
$n$ & 0.7407 & 0.49 & 0.695 & 0.72 & 0.6805 & 0.62 \\
$R_{\mathrm{ct}}\left(\Omega \cdot \mathrm{cm}^{2}\right)$ & 1434 & 3.76 & 360.4 & 1.56 & 379.0 \\
\hline
\end{tabular}

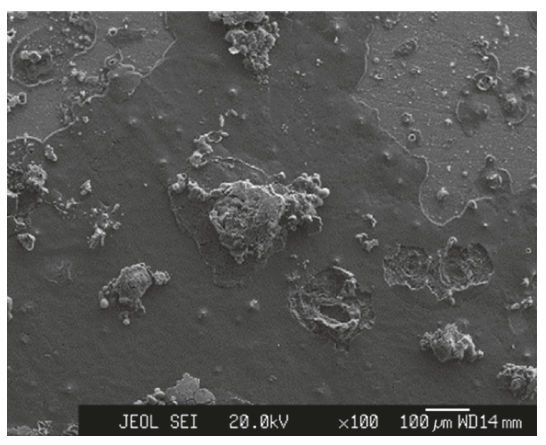

(a)

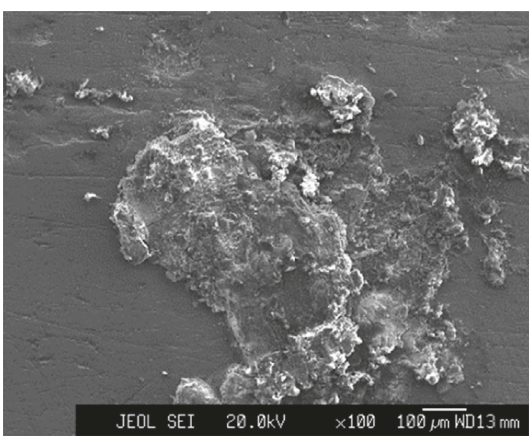

(b)

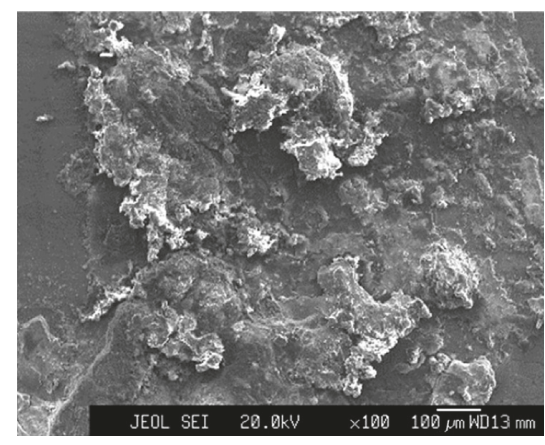

(c)

FIGURE 5: Corrosion products of WMs at welding heat inputs of (a) $10 \mathrm{~kJ} / \mathrm{cm}$ and (b) $20 \mathrm{~kJ} / \mathrm{cm}$, and (c) Q690 BM following electrochemical testing.

and Q690 BM (\#3), which presented better passivation behavior of the WM at low welding heat input. As presented in Figure 3(c), the Bode-phase curves of \#2 and \#3 displayed certain constant plots at the middle frequency range. The phase angle values remained close to $55^{\circ}$ for $\# 2$ and \#3, which demonstrated the formation and growth of the corrosive products at middle frequency $[19,20]$. It further confirmed the improved EIS behavior of the WM at low welding heat input than at high welding heat input of the WM and Q690 BM.

To simulate the measured impedance data, the equivalent circuit presented in Figure 4 was utilized [21] as a onetime constant capacitor model. In this equivalent model, $Q$ represented the constant phase angle element; $R_{s}$ represented the solution resistance, while $R_{\mathrm{ct}}$ represented the charge transfer resistance as well as the polarization resistance, which could be defined as the sample resistance in the solution; and $n$ represented the electrical capacitor parameter of the ideal condition of 1 as to a completely parallel capacitor. The variation of the impedance parameters of all samples in the $3.5 \mathrm{wt} . \% \mathrm{NaCl}$ solution is illustrated in Table 5. The simulation results indicated that the low welding heat input could significantly improve the WM corrosion resistance, which significantly decreased compared to the
Q690 BM. In other words, the low welding heat input contributed to the galvanic corrosion risk reduction between the WM and the Q690 BM.

3.3. Corrosion Product Analyses. The corrosion products of WMs at different welding heat input conditions and the Q690 BM following electrochemical testing were observed with SEM, as presented in Figure 5. It was apparent that all sample corrosive products demonstrated a localized corrosion behavior. The corrosive products of the WM at $20 \mathrm{~kJ} / \mathrm{cm}$ and the BM were similar, as presented in Figures 5(b) and 5(c), respectively, where abundant corrosive products were generated on the surfaces. This result was well explained and highly consistent with the corresponding similar LRP and $R_{\mathrm{ct}}$ values of the WM at $20 \mathrm{~kJ} / \mathrm{cm}$ and BM. Due to the porous corrosive products covering the surfaces, the experimental solutions were easy to penetrate these products and reach the matrix, consequently accelerating the matrix corrosion. The WM prepared at $10 \mathrm{~kJ} / \mathrm{cm}$ low welding heat input presented high resistance values as well as a relative favorable corrosive surface morphology, where low-sized pitting corrosion and a certain amount of 
corrosive products could be observed on the surfaces as presented in Figure 5(a). Researchers [22, 23] discovered that the corrosion resistance of steels comprising various ferrite fractions was primarily determined by the galvanic corrosion resistance between the constituents of the ferrite phase and of other phases. In this work, fine grain sizes and high ferrite content in the low heat input WM were effective in the formation and growth prevention of corrosive products, which contributed to its favorable resistance value in the $3.5 \mathrm{wt} . \% \mathrm{NaCl}$ solution.

3.4. Discussion. The weld joint consisted of different regions, where galvanic corrosion should not be neglected because it could lead to accelerated deterioration of the anodic region, especially in offshore environments. In the case of LP results, due to these corrosion potential differences, the BM in the welded structure acted as an anode, while the WM acted as a cathode when the joint was exposed to an aggressive environment. Therefore, the attached BM would be anodically polarized through galvanic interaction with the WM. Owing to a high anodic area of the attached BM, the galvanic corrosion of the structure could be reduced. Furthermore, the potential of the $20 \mathrm{~kJ} / \mathrm{cm}$ higher heat input WM sample displayed a lowest negative value, whereas the potentials of the $10 \mathrm{~kJ} / \mathrm{cm}$ lower heat input WM and the Q690 BM were quite higher and approximately similar. Consequently, the galvanic effect could also be less in the lower heat input WM case.

In the other case of resistance response, the acicular ferrite phase and the fine grains in the $10 \mathrm{~kJ} / \mathrm{cm}$ low heat input WM contributed to the corresponding highest LRP and $R_{\mathrm{ct}}$ values. Through the welding heat input increase, the bainite and M-A phases grew and the ferrite phase was reduced, as a result of the WM resistance decrease. When the low heat input WM was coupled with the BM, the BM would act as the anode. Therefore, the BM might become the cathode once coupled with the high heat input WM, due to the corresponding higher $R_{\mathrm{ct}}$ value compared to that of the WM. From this perspective, the risk of galvanic corrosion of the structure could be further reduced in the lower heat input WM case.

According to the aforementioned analysis and based on the theory of galvanic corrosion, the $10 \mathrm{~kJ} / \mathrm{cm}$ low welding heat input contributed to the galvanic corrosion minimization during the FCAW of the Q690 steel.

\section{Conclusions}

(a) $10 \mathrm{~kJ} / \mathrm{cm}$ of low welding heat input contributed to the fine grain size and high content of the acicular ferrite phase in the WM during flux-cored arc welding of the Q690 HSLA steel. Owing to its similar potential to the $\mathrm{BM}$ and the high anodic area of BM, the low FCAW heat input would minimize the inclination of galvanic corrosion in the welding structure.

(b) At the high heat input of $20 \mathrm{~kJ} / \mathrm{cm}$, the WM grains grew significantly near the entire bainitic transformation to form higher-sized lath and granular bainite with certain M-A islands, where the WM was prone to galvanic corrosion due to its low potential and transfer resistance.

\section{Conflicts of Interest}

The authors declare that they have no conflicts of interest.

\section{Acknowledgments}

This research was supported by the National Natural Science Foundation of China (no. 51601043), the Scientific Program of GDAS (2016GDASPT-0205), and the Technical Project of Guangdong and Guangzhou (2014B050503004, 2016B090918120, 201704030112, 201604046026).

\section{References}

[1] X. Z. Chen, Y. M. Huang, and Y. C. Lei, "Microstructure and properties of $700 \mathrm{MPa}$ grade HSLA steel during high temperature deformation," Journal of Alloys and Compounds, vol. 631, pp. 225-231, 2015.

[2] X. Z. Chen and Y. M. Huang, "Hot deformation behavior of HSLA steel Q690 and phase transformation during compression," Journal of Alloys and Compounds, vol. 619, pp. 564-571, 2015.

[3] W. H. Zhang, X. P. Liu, and Y. Tao, "Development of Q690 high-strength steel for modular vehicle," Science and Technology Innovation Herald, vol. 34, pp. 88-89, 2012.

[4] Y. Lou, H. Xiao, Y. Peng, A. Wang, Z. L. Tian, and Z. H. Peng, "Study on microstructure and properties of welded joints of a 690 MPa grade HSLA steel," Materials Science and Technology, vol. 20, no. 2, pp. 101-107, 2012.

[5] C. Fang, X. Meng, Q. Hu et al., "Welding of Q690 steel used in hydraulic support," Journal of Iron and Steel Research, International, vol. 19, no. 5, pp. 79-85, 2012.

[6] E. Bonneviea, G. Ferriere, A. Ikhlef, D. Kaplan, and J. M. Orain, "Morphological aspects of martensite-austenite constituents in intercritical and coarse grain heat affected zones of structural steels," Materials Science and Engineering: A, vol. 385, no. 1-2, pp. 352-358, 2004.

[7] C. T. Kwok, S. L. Fong, F. T. Cheng, and H. C. Man, "Pitting and galvanic corrosion behavior of laser-welded stainless steels," Journal of Materials Processing Technology, vol. 176, no. 1-3, pp. 168-178, 2006.

[8] Z. Zhang, H. Jing, L. Xu, Y. Han, and L. Zhao, “The influence of microstructural evolution on selective corrosion in duplex stainless steel flux-cored arc welded joints," Corrosion Science, vol. 120, pp. 194-210, 2017.

[9] H. N. Farneze, J. F. Jorge, L. G. Souza, and I. S. Bott, "Comparative study of high-strength steel weld metals obtained by the SMAW and FCAW processes for offshore applications and mooring chains," Welding International, vol. 24, no. 12, pp. 903-910, 2010.

[10] I. A. Ibrahim, S. A. Mohamat, A. Amir, and A. Ghalib, "The effect of flux core arc welding (FCAW) processes on different parameters," Procedia Engineering, vol. 41, pp. 1497-1501, 2012.

[11] J. J. Coronado and C. Cerón, "Fracture mechanisms of CTOD samples of submerged and flux cored arc welding," Theoretical and Applied Fracture Mechanics, vol. 53, no. 2, pp. 145-151, 2010.

[12] S. Mukhopadhyay and T. K. Pal, "Effect of shielding gas mixture on gas metal arc welding of HSLA steel using solid 
and flux-cored wires," International Journal of Advanced Manufacturing Technology, vol. 29, no. 3-4, pp. 262-268, 2006.

[13] S. Jindal, R. Chhibber, and N. P. Mehta, "Issues in welding of HSLA steels," Advanced Materials Research, vol. 365, pp. 44-49, 2012.

[14] X. Z. Chen, Y. Y. Fang, P. Li, Z. Z. Yu, X. D. Wu, and D. S. Li, "Microstructure, residual stress and mechanical properties of a high strength steel weld using low transformation temperature welding wires," Materials and Design, vol. 65, pp. 1214-1221, 2015.

[15] J. Hu, L. X. Du, J. J. Wang, and C. R. Gao, "Effect of welding heat input on microstructures and toughness in simulated CGHAZ of V-N high strength steel," Materials Science and Engineering: A, vol. 577, pp. 161-168, 2013.

[16] Q. B. Du, C. Y. Ma, Y. Peng, Y. J. Zhang, and H. K. Wang, "Effect of heat input on microstructure and performance of weld metal for Q890 high strength steel," Material Science and Technology, vol. 21, pp. 143-148, 2013.

[17] S. Qu, Y. Zhang, X. Pang, and K. Gao, "Influence of temperature field on the microstructure of low carbon microalloyed ferrite-bainite dual-phase steel during heat treatment," Materials Science and Engineering: A, vol. 536, pp. 136-142, 2012.

[18] S. Qu, X. Pang, Y. Wang, and K. Gao, "Corrosion behavior of each phase in low carbon micro alloyed ferrite-bainite dualphase steel: experiments and modeling," Corrosion Science, vol. 75, pp. 67-77, 2013.

[19] L. R. Bhagavathi, G. P. Chaudhari, and S. K. Nath, "Mechanical and corrosion behavior of plain low carbon dualphase steels," Materials and Design, vol. 32, no. 1, pp. 433-440, 2011.

[20] A. Fattah and S. Vafaeian, "Comparison of electrochemical behavior between coarse-grained and fine-grained AISI 430 ferritic stainless steel by Mott-Schottky analysis and EIS measurements," Journal of Alloys and Compounds, vol. 639, pp. 301-307, 2015.

[21] L. Jinlong and L. Hongyun, "Electrochemical investigation of passive film in pre-deformation AISI 304 stainless steels," Applied Surface Science, vol. 263, pp. 29-37, 2012.

[22] J. Soltis and K. A. Lichti, "Galvanic corrosion of carbon steel coupled to antimony," Corrosion Science, vol. 68, pp. 162-167, 2013.

[23] H. Y. Ha, M. H. Janga, T. H. Lee, and J. Moon, "Interpretation of the relation between ferrite fraction and pitting corrosion resistance of commercial 2205 duplex stainless steel," Corrosion Science, vol. 89, pp. 154-162, 2014. 


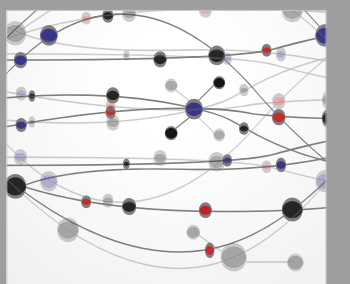

The Scientific World Journal
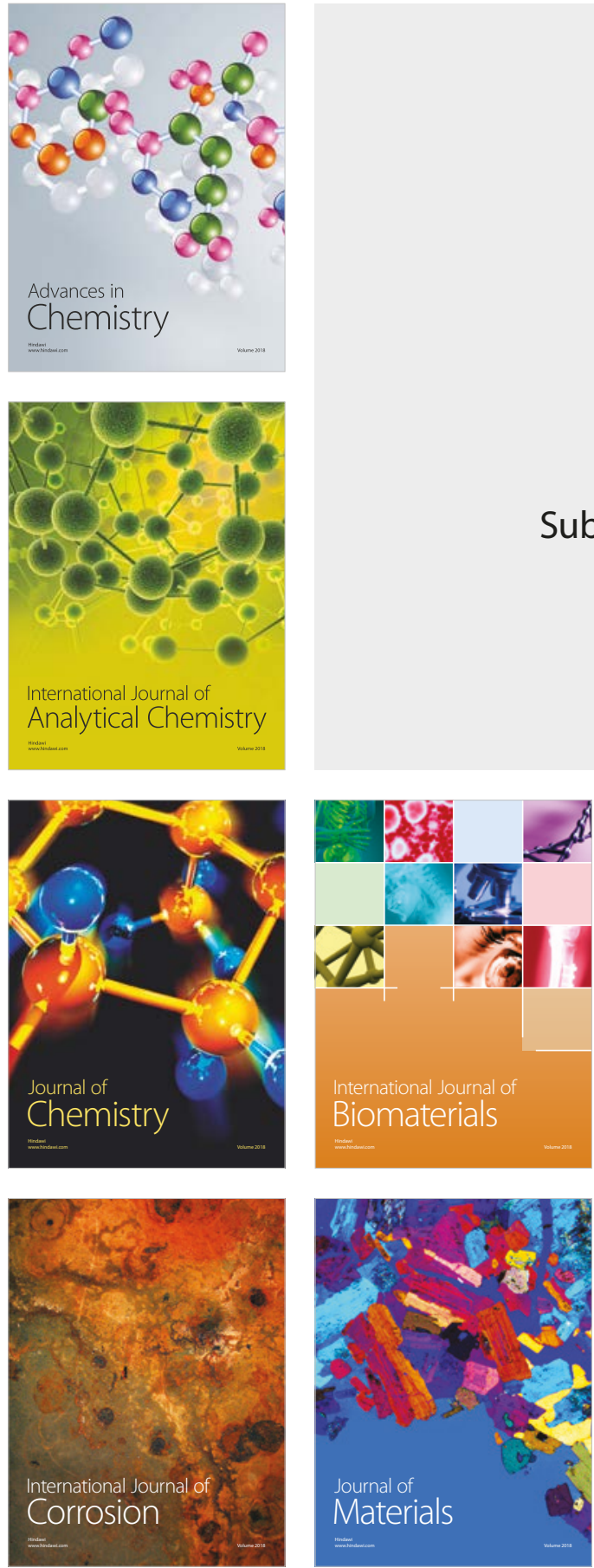

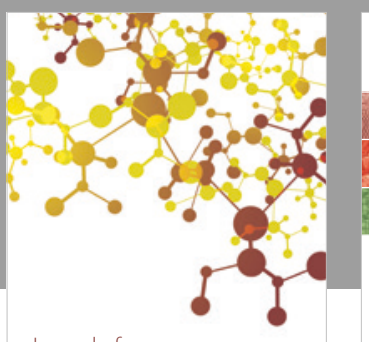

Journal of

Applied Chemistry
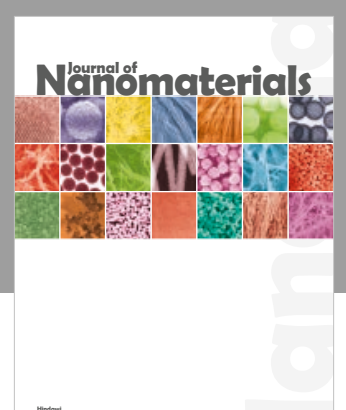

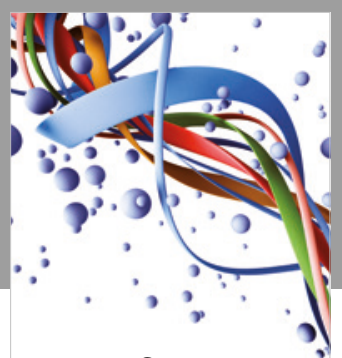

Scientifica

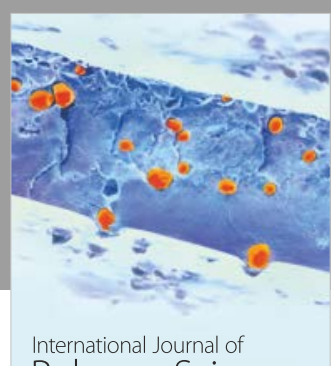

Polymer Science

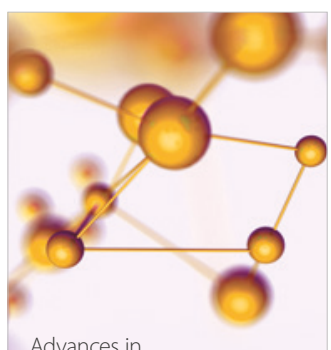

Physical Chemistry
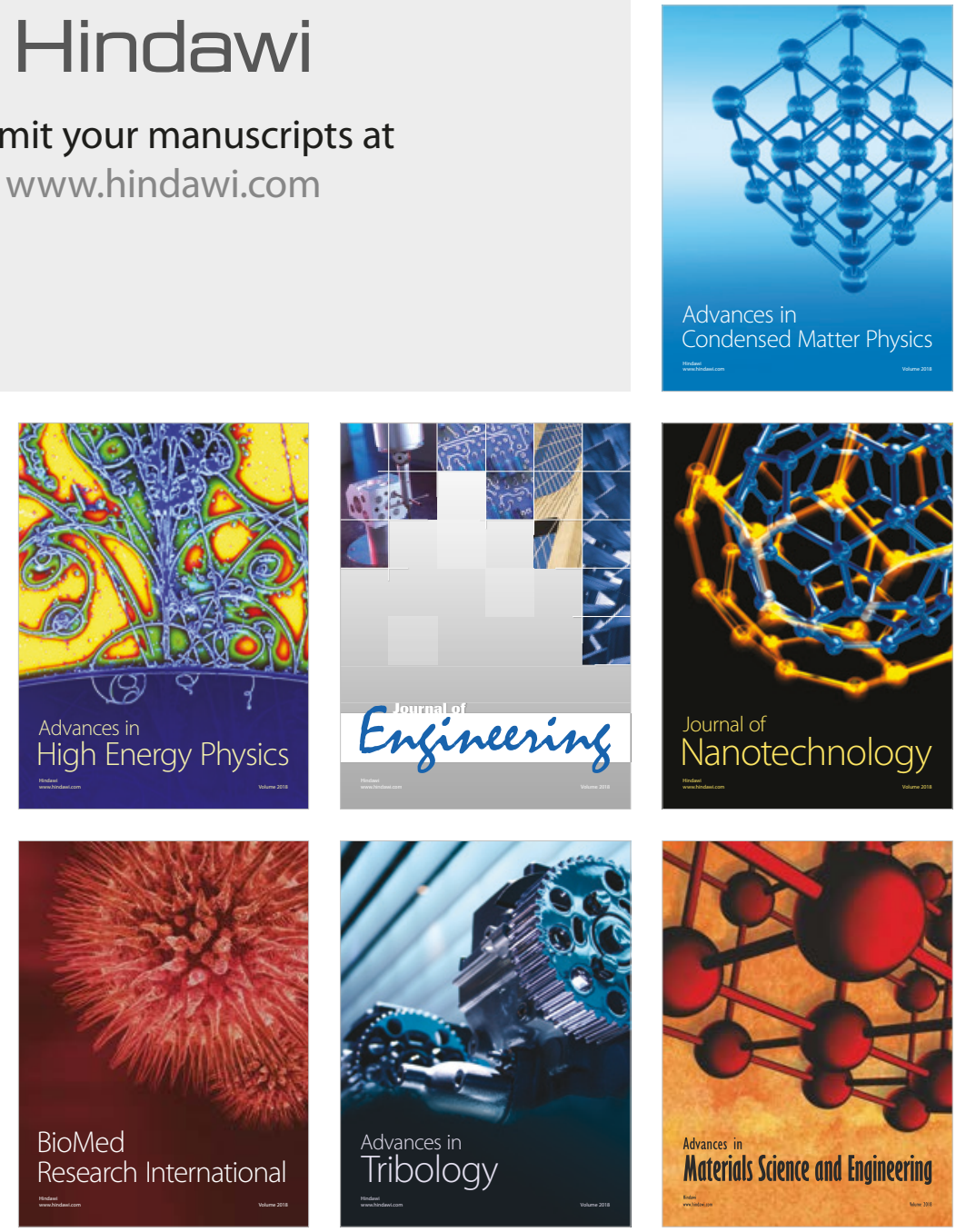